\title{
Left Circumflex Artery Ostium
}

National Cancer Institute

\section{Source}

National Cancer Institute. Left Circumflex Artery Ostium. NCI Thesaurus. Code C116176.

The opening of the left circumflex artery at its origin. 